\title{
MORAL OUTRAGE: TERRITORIALITY IN HUMAN GUISE
}

\author{
by Ward H. Goodenough
}

Abstract. Moral outrage is a response to the behavior of others, never one's own. It is a response to infringements or transgressions on what people perceive to be the immunities they, or others with whom they identify, can expect on the basis of their rights and privileges and what they understand to be their reasonable expectations regarding the behavior of others. A person's culturally defined social identities and the rights and privileges that go with them in relationships to which those identities can be party make up the contents of that person's social persona and also constitute that person's social territory. Infringements of rights and privileges in the social and symbolic worlds in which humans live are the equivalent of encroachments on territory among animals, and moral outrage can be understood as the human expression of what we perceive as territorial behavior in animals. As emotion, outrage is affected by such clinical processes as displacement, rationalization, projection, and reaction formation. Outrage has an essential role in the maintenance of viable social groups, but it also exacerbates conflict among people who perceive one another as "others."

Keywords: emotion; immunities; morality; moral outrage; rights; territoriality.

I doubt that any of us can think of a time when we were morally outraged at something we did ourselves. Angry with ourselves? Yes. Distressed, stricken with remorse, overcome with shame or guilt? Yes, to all of them. But morally outraged, filled with righteous wrath? No.

Moral outrage is an emotional response to what other people do, not to what we do ourselves. The same act by someone else, furthermore, may outrage me on one occasion and not on another. If someone is arrogant toward my children, for example, and subjects them to gross insult, I am

Ward H. Goodenough, a cultural anthropologist, is University Professor Emeritus at the University of Pennsylvania. He presented this paper at the Fortieth Annual Conference of the Institute for Religion in an Age of Science (IRAS), "Charting Our Lives: Possibilities, Constraints, Decisions,” at Star Island, New Hampshire, 31 July-7 August 1993. 
likely to be outraged. If someone does the same thing to a public figure for whom I have a strong dislike, I may, on the contrary, take pleasure from it, feeling that person had it coming. What makes someone's behavior morally outrageous is not intrinsic in the behavior itself but has something to do with how it relates to us and to what is important to us. We can think of what is moral in absolute terms, but we must recognize that breaches of morality affect us emotionally in quite different ways, depending on how we relate ourselves to the breach. If we are to understand moral outrage as an emotional phenomenon and what it is that triggers it in us, we must look not simply at actions but at actions in the context of our relations with other people; and we must examine what it is about ourselves in our relations with others that makes us liable to be outraged in the course of our dealings with them.

To clarify further what I am getting at, think of how we react if the automobile we are driving has a mechanical failure. If a friend of ours has given us the use of his or her car as a loan, we do not feel outraged by the event. We may worry about our own possible responsibility for the failure; and we may be concerned that our friend not feel badly about having let us down with a defective car. We don't want it to become a problem between us. Suppose, however, that the mechanical failure is in a car that we bought new just a week earlier. Even though the guarantee will presumably cover the cost of repair, we nonetheless feel that we have been had. This was not supposed to happen. The warranty that came with the new car made it clear that we had a right not to have this happen. And when we feel that our rights under the rules of society have been breached, we are likely to respond with some degree of moral outrage. But why? Why should what we call our rights make such a difference in our emotional response?

Before we try to answer this question, we must also consider the fact that what we regard as outrageous behavior-behavior, that is, that evokes moral outrage-may be directed at other people and not at ourselves. Such behavior, as I have indicated, may or may not evoke feelings of outrage in us and yet be judged as outrageous because we recognize it as the kind of act that is likely to provoke feelings of outrage in some others, even if not in us. Our rights are not being violated, but the rights of others are. Such violations may evoke strong feelings of outrage within us, but whether we can act on those feelings, and how, depends on what we perceive to be our standing in relation to the action, as has been persuasively shown by John Sabini and Maury Silver (1982). We may feel outraged but not feel free to express it, or we may not feel outraged at all. Depending on how we stand in relation to an act and to the person committing it, moreover, we may feel morally exercised rather than outraged, or we may be only mildly concerned. 
I argue that there are four factors governing these differences in degree of moral concern. One is the extent to which we identify with the victim of outrageous behavior. It makes a difference whether the victim is a close friend or someone we do not know. Another factor, by contrast, is the extent to which we identify with the person committing the outrageous behavior. Something done by a member of our family, whom we are committed to protect and care for, may leave us morally concerned or even exercised, but whether we express moral outrage toward that family member in public or even in private will depend on what our other obligations are to him or her and also to the persons affected by the act. In Chuuk (formerly Truk) in Micronesia, for example, if persons commit outrageous acts against someone else in their community, their next of kin in a position of authority in regard to them may publicly subject them to a severe beating, thus giving expression to the feeling of public outrage and making it unnecessary for the kin of the victim to take retaliatory action.

A third factor is the extent to which the rights being violated are rights in which we also share, such sharing, of course, being one of several bases for our identifying with the victim. Such violation, moreover, puts the continued honoring of our own similar rights in jeopardy. If it could happen to someone else, it could happen to me. In the Gilbert Islands, for example, to steal from a fellow member of one's community was traditionally regarded not only as heinous in the extreme but as disqualifying the thief from being considered a fellow member of Gilbertese society. Every member of a community had a duty to respect the property of everyone else in the community. Immunity from theft was shared by all. To pilfer from the visiting ships of strangers, people to whom one had no obligations as a fellow community member, was, by contrast, acceptable behavior.

The fourth factor affecting how outraged we feel is the importance we attach to the rights being violated. Of necessity we prioritize what we regard as rights. My right to a parking place has low priority, for example, alongside of someone else's right to emergency medical service. As this example indicates, the social context in which a right is being violated makes a big difference in how we react to the violation.

But why am I talking about rights? Do I mean to imply that moral outrage has to do with rights, with what is involved in publicly sanctioned and, in that sense, jural relationships? Does morality not transcend the jural? Is there not a higher morality? Indeed, there may be. But publicly sanctioned rules of behavior exist as expressions or implementations of our moral sense, whatever that may consist of. Violation of these rules is by that fact a justifiable basis for outrage. Moral outrage is anger that we consider justifiable. We may feel angry for other 
reasons, but we do not feel that we have a basis for moral outrage unless we can justify a claim that either our personal rights or what we regard as basic human rights are being violated. ${ }^{1}$ We may regard the violated rights as inalienable, as deriving from customary practice, or as established by a contract or a promise. If we think that public decency requires respect for people's feelings, we must remember that people's feelings stem in large part from what they regard as their rights and the rights of others, not just as codified in law but as understood from the unwritten rules by which people live together.

In societies without writing, all the rules by which people live are unwritten. Many of them are verbally articulated, however, and there are likely to be persons who are publicly recognized as having authoritative knowledge regarding them and the right to give them verbal articulation. But even in literate societies - and our own is no exceptionmany of the rules are not stated verbally. People know them subjectively in the way they know the grammatical rules of their language. They have a feel for them. It is perhaps better to call them principles rather than rules and to reserve the term rule for a principle that has been expressed verbally. Moral outrage may be seen as arising from the violation of what is felt to be such a socially shared principle, especially when the violation breaches an immunity that persons feel the principle makes rightfully theirs. It is this sense of right arising from unverbalized principles governing social relationships (as well as from the verbalized and written rules) that gives rise to moral outrage as distinct from other forms of anger. In this respect, what we consider moral clearly reflects something deeper than rights and immunities that derive only from verbal and written social rules. In this regard, we should note how a community of dogs, richly described by Elizabeth Marshall Thomas (1993), developed and maintained a social order in which each dog knew its place within the community's dominance hierarchy and honored the expectations of the other dogs in the community accordingly. If it was not a moral community, it was certainly a principled one. ${ }^{2}$

If principles are unexpressed verbally, how is it that people acquire a feel for them? One way is by observing what angers others with whom they live. Children do things that make their parents angry. Other people do things that make their parents and other significant adults angry. Socialization, moreover, involves calling to children's attention when they, or others, are doing things that are socially unacceptable, just as they get lapses in speech corrected. The underlying principle from which that unacceptability arises may not be stated, but over time and with recurring examples of what is unacceptable, children get a sense of what does and does not go - of the kinds of things people should not have to experience - and it is this sense that constitutes what I am calling a principle. The 
process of experiencing reproach from others for specific acts in specific situations is what crystallizes a working social consensus regarding such principles among members of a group. It also produces what constitutes an underlying moral sense in individuals (Sabini and Silver 1982, 43).

At least as important as reproach is imitation. The biologically builtin capacity and even compulsion to imitate closely associated conspecifics, I believe, underlies empathy. Through imitation, individuals develop patterned ways of doing things on the model of others and, in doing so, also develop a feel for the principles inherent in those patterns. Ordinarily we think of imitation as actively trying to do what we see another doing. But the mechanisms, whatever they are, that allow us to do that must also allow us vicariously to experience what we see another experiencing, especially if we have had similar experiences ourselves. The capacity for empathy or compassion is obviously essential if one is to be able to feel moral outrage at others' experiences as well as one's own.

People often disagree about what the verbal and written rules should be. Within a society, these disagreements have to do very largely with prioritization of principles. Do property rights take priority over survival rights, for example? Under what circumstances do individual rights take priority over group rights, and vice versa? Competing ideologies stemming from subcultural differences among groups within the larger society may produce such disagreement. Different advantages and disadvantages within the opportunity structure of a society also may produce disagreement about priorities and give rise to competing ideologies. ${ }^{3}$ Here outrage can be differentially associated with what people intuitively feel the principles and rules ought to be, especially as they relate to the priorities governing their application. These differences do not mean that people lack a moral sense. They are differences only in how each individual's moral sense is constituted.

It is not enough to say that a moral sense crystallizes within each of us individually in the course of socialization, and that it continues to be reinforced by instances of transgression and reactions of outrage and comment on them by others. We must still ask why it is that the emotion of moral outrage is apparently a universal natural human response to violations of what people feel or explicitly understand to be their rights and the immunities that follow from them. Where in our psychobiological makeup does the feeling of outrage come from? In the context of culturally and symbolically constructed social life, is it an expression of something that is manifested in animal behavior more generally? I argue that it is.

I have by now touched on a number of things that bear on our trying to understand moral outrage. Outrage is a response to what people 
perceive as violations of their rights or justifiable expectations and those of others, and, I should add, to proposals to alter their rights and expectations. Their rights derive from a system of understandings within a community as to what is unacceptable in the members' dealings with one another, understandings that define not only each individual's rights in relation to others but also what is right.

As justifiable anger, then, moral outrage involves both emotion and what people perceive to be the right way for people to deal with one another, including what they see as their rights, which form a part of what is right. Emotions are engendered by experience and are something people learn how to manage in the course of socialization. Their techniques of management affect how they express their outrage. I consider some of these techniques in a later part of this discussion. Rights are the other major topic we must consider. They involve expectations relating to the self in interaction with others: what we can demand of others and what they can demand of us. So we must consider rights in relation to the composition of social selves or personae.

\section{THE SELF IN CUlTURALly STRUCTURED SOCIETY}

The sense of self of any animal, to the extent that it has one, can arise only from its experience of itself in varied contact with its environment. I am not here talking about having an awareness of self but of having a subjective sense of self that is manifested by the characteristic ways an animal disposes itself toward its environment. Such characteristic or habitual dispositions develop from the ways an animal has experienced its environment. A dog that has been repeatedly abused as a puppy disposes itself to people, for example, differently from one that has not been abused, and its subjective sense of self in relation to people is correspondingly different.

As social creatures, humans experience themselves very largely in the course of dealings with other people, Like other animals, humans develop characteristic ways of disposing themselves toward people and things according to their experiences in dealing with them and according to how their individual temperaments affect the way they respond to what they experience. What they experience, moreover, is already a product of the habitual dispositions of those with whom they interact. A person's characteristic dispositions of self can be seen as constituting that person's subjective sense of self. Observing these characteristic dispositions in others, we see them as aspects of their personalities.

Human experience of self, unlike that of other animals, is accompanied by talk. Infants are talked to. What they experience physically and emotionally is labeled by words, and the occasions of experience are contextually labeled. A significant part of this contextual labeling con- 
sists of verbal definitions of who and what we are: girl, boy, good, bad, stupid, capable, and so on. Labeling also designates who and what others are-others with whom we deal and others with whom we don't deal (with explanations of why we don't deal with them). The labels that apply to us vary in accordance with the labels that apply to those with whom we deal: as a brother to a brother, a sister to a sister, a sister to a brother, a child to an adult, a household member to a guest, a young woman to a suitor, and so on.

It is largely in connection with such labeling of persons and relationships that we experience ourselves as social persons and that we develop or acquire our social selves and our ways of disposing ourselves toward others. Crucial in such experience are the things we learn in connection with the positive and negative reinforcements of reward and punishment, praise and criticism. The things we learn are what we can rightfully expect of others and what others can rightfully expect of us. We also learn these expectations as observers of the social dealings of others, seeing how our parents dispose themselves in different ways to different others, such as kin, neighbors, tradesmen, police, and so on. From all of this we develop subjective expectations about what is and is not acceptable behavior in different relationships.

Labeling of persons and relationships also greatly facilitates the development of self-awareness. There is good evidence of self-awareness in chimpanzees (Goodall 1986), but language provides a vehicle for framing the different contexts and relationships within which humans are aware of themselves. It provides, in short, the terms by which we objectify ourselves to ourselves as persons and by which we conceptualize ourselves as social beings in relationships with other social beings.

The kinds of social relationships in which we participate differ. We experience ourselves differently as we go from one kind of relationship to another. On the one hand, for example, social living makes people important instruments in the gratification of one another's wants. Hence the need for cooperation. On the other hand, social living puts people in competition for things they want. This is true of other social animals as well. There are contexts in which they share, and there are contexts in which they do not share but assert themselves against one another and establish dominance hierarchies. ${ }^{4}$

Among humans, language transforms sharing and dominance relations into what are seen as legitimate expectations. Dominance and sharing do not disappear, but they become regularized by the establishment of explicit understandings, formulated in words, as to what category of person has a right to what in relation to another category of person. Members of the same family have a right to share in certain things as they need them. Parents have a right to demand obedience 
from their children in relation to certain things. Every family member has a right to an equal share of an unexpected delicacy. In relation to some undertakings, each participant is entitled to a share of the return in proportion to how much that participant contributed toward acquiring it. Similar explicit understandings obtain in relations with members of one's larger community who are not close kin.

So it is that in all human societies of which we have record, social relationships are ordered in terms of rights and duties that pertain to comembership in groups and to dealings between various categories of person and categories of subgroups within the larger group. By a right, I mean a publicly recognized claim that one person can make on another with the expectation that the other has a duty to honor it. A claim that is publicly perceived as out of order is not a right.

I can demand of my neighbors that they refrain from gardening on my land without my permission. I have a right, and they have a duty to honor it. I cannot demand of my neighbors that they maintain a flower garden on their land. That is something in regard to which I have no right, and they have a privilege. Rights and privileges give those who hold them jural immunities. In the examples just given, I have immunity from my neighbors' expanding their garden onto my land, and my neighbors have immunity from curtailment of their freedom to garden or not as they please on their land. At the same time, my neighbors' privilege makes me liable to have to put up with results of their gardening efforts on their land that I find distasteful, for I have no right to demand that they do otherwise. And if my neighbors get my permission to garden on my land, they are liable to my withdrawing that permission at a future date. So, in the language of jurisprudence (Hohfeld [1919] 1946), we find that all human social relations are ordered in terms of rights and duties. Where A has no rights in A's dealings with B, $\mathrm{B}$ has privilege and is free to do what B wants. A's privileges and rights give A immunity from B's doing things that infringe on them, and they make B liable to having the pursuit of B's own wants interfered with by A. Thus, by allocating rights and duties among categories of persons, humans use language to give structure to what we perceive in animals as sharing, dominance, and mutual toleration.

The cultural ordering of sharing and dominance relationships brings us back to consider further what I referred to earlier as the different kinds of relationships in which people experience themselves and from which they derive their socially recognized personhood. Following Alan Fiske (1991), let us consider four such kinds or, better, modes of relationship in which rights, privileges, and immunities are necessarily distributed differently. These modes appear to be present in all human societies, but their relative importance and the subject matters to which 
they apply differ considerably.

One of these modes is communal sharing on a basis of who is in need, as in a family. There is no sense that people's entitlements depend on the degree of their contribution to the group. From each according to his or her ability and to each according to his or her need is the governing principle. Another mode, to which I have already referred, is hierarchical, assigning priorities of right according to authority and social rank. The boss, giving the orders, has more rights than the employees, who do what they are told in the work situation. Still another mode is that in which everyone expects identical treatment in the sense that no one is entitled to more or less than anyone else. Every child at the birthday party gets exactly the same number of candies and favors, for example, regardless of social popularity or any other discriminating consideration. A fourth mode involves the assessment of the relative power, worth, and value of the participants and their potential contributions to the relationship, as in negotiating a peace treaty or a business deal. The rights and immunities of the respective parties are determined by agreements and promises they enter into and are essentially contractual in nature..$^{5}$ Each of these modes has its own basic pattern of rights and obligations, and implicit in each such pattern is an accompanying ethic, a notion of what is fair or equitable; and when something happens that people perceive as unfair within the relevant mode, they are likely to be outraged.

Analogues to communal sharing and rank ordering are evident, as I have already indicated, in the sharing and dominance behavior of Old World apes and monkeys. Rudiments of the contractual mode are also found in the formation of alliances between higher-ranking and lowerranking individuals in chimpanzee communities (de Waal 1994); and the equality matching mode appears to be foreshadowed in the reciprocal behavior relating to grooming and food sharing among adult chimpanzees (de Waal 1989, 1991).

It is remarkable how readily people switch from mode to mode in everyday activity, depending on whom they are dealing with and what is the context of their dealings. A mother and her grown daughters, working together in the mother's kitchen to prepare a Thanksgiving Day dinner, operate largely in communal sharing mode. Each keeps an eye out for what needs to be done next and moves in to do it. Nobody is keeping score as to who does what. If one feels like sitting for a bit, she does so without feeling guilty about it. There are points where the mother may shift into authority mode, however, telling one of her daughters not to bother with what she is doing now and directing her to do something else she feels is more urgent at the moment. They are working in her home in her kitchen, and she is therefore tac- 
itly understood to be in charge of the operation which they are cooperatively sharing. While this work is going on, a grandson comes in to ask if he can go next door to visit a neighbor boy. His mother looks to the grandmother, who says that if he will first take out the garbage, it will be all right for him to go over for an hour, but no longer than that, because dinner will be almost ready then. Here we have a sequence of shifts, first into authority mode (asking permission and mother looking to grandmother) and then into contractual mode, in which a bargain is struck: being allowed to go next door in return for taking out the garbage. Following this, a daughter who has brought a box of chocolates for after dinner opens the box and puts the chocolates in a dish. In strict equality mode, she doles out one each to her mother, her sisters, and herself as a little treat.

If one of the sisters sat in the living room reading the newspaper without ever lifting a hand to help, she would be perceived as behaving inappropriately. The others would be likely to wonder why she was behaving this way. They might well ask one another, "What's eating Helen?" If one of the sisters began to take charge of the operation in her mother's kitchen without a by-your-leave, she would be judged out of order too. If the grandson had refused to take out the garbage, he too would have been out of order, for refusing to recognize his obligations in an authority relationship. If the grandmother had imposed onerous conditions on his going next door, she would have been out of order in contract mode. Finally, if the sister who brought the chocolates had taken one for herself without giving one to each of the others present, if she had given one to one sister but not to the others, if she had given more to one sister than to another, or if she had tried to bargain with her sisters in regard to how many each would get, she would have been behaving wrongly in a situation in which equitable dealing called for treating everyone present in exactly the same way.

None of the understandings about what is and is not appropriate in the little scenario I have just presented is formally codified. Yet the participants have a clear sense of what is and is not acceptable, and how what is acceptable varies from one interactive mode to the next. Unacceptable behavior is a violation of what the participants feel they can justifiably expect from one another, a violation, that is, of what they consider to be their rights and the violator's obligations as comembers of a social group and as coparticipants in interactions and activities within that group. And it is not just a violation of their individual rights, but of what they feel to be right.

How people react to violations depends on how they see themselves as related to one another in other ways. The daughter who takes no part and remains in the living room reading the newspaper is accepted as a member 
of the family. Her withdrawal, if it is seen as out of character, leads to concern about what may be bothering her. Some indignation may be felt, but its expression is not appropriate to the maintenance of their familial relationship. If her failure to take part were seen as characteristic behavior, however, the others would not wonder what was bothering her and would be more open in expressing their feeling of annoyance.

The example I have given involves members of a family. They are all bound to one another by intimate ties built in a history of mutually positive reinforcement and interdependence. Each one's sense of self involves importantly her ties to the others. Who each one is derives in significant part from what they all are as a family group. I have already noted that we do not feel moral outrage at things we ourselves do. By extension, we are not likely to feel moral outrage at things that people do if we feel closely identified with them. We may feel hurt, annoyed, angry, shamed, and even shocked, as we might by our own behavior, but not outraged. We are outraged when inappropriate behavior is exhibited toward us, or toward those with whom we identify, by people with whom we do not closely identify ourselves-by people we think of as others rather than as us, but as others who are still presumably bound by the same expectations as we are in regard to what is appropriate behavior. We grieve when we find our trust betrayed by a close family member who is an extension of ourselves; we are outraged when we find our trust betrayed by someone in our larger community who is not a close family member. Then our hackles really get up.

If a well-liked uncle embezzles money from the family reunion fund, for example, we are likely to be angry at what he did and morally concerned but not morally outraged, making allowance for his human frailty. He is still our uncle, and we have to go on living with him as such. But if the president of the bank in which we have deposited our savings does the same thing, we are likely to express outrage. The attack on Pearl Harbor in 1941, to take another example, was one we called a sneak attack on us by a country whose people we saw as different from ourselves but, at the same time, as a party with us to understandings about appropriate behavior in international relations and rules of warfare. The reaction of the great majority of Americans was typical of moral outrage. In Bosnia, members of each of the ethnic groups in the three-way civil war there are morally outraged at what members of the other groups are doing but tend to make excuses for what is done by members of their own group, by the people with whom they identify and with whom they are identified by others.

\section{OUTRAGE AND TERRITORIALITY}

Moral outrage, I have been arguing, is something we feel in response to 
intrusions on our rights and on the rights of those with whom we identify by those with whom, by comparison, we do not identify. This point is crucial to any understanding of what moral outrage represents as a kind of behavior that is universal among humans regardless of cultural differences among them, and therefore presumably rooted in a predisposition for which we humans are psychobiologically programmed. Is this predisposition something peculiarly human? Or can we understand it as a manifestation in humans of something present in other animals and therefore evolutionarily a part of our prehuman heritage?

To explore this question, let us examine one more homely example. Think of the twelve-year-old boy in the family whose mother catches him stealing a handful of cookies from her cookie jar. He knows he is not supposed to take cookies without her permission. Contrast her feeling in this case with how she would be likely to feel if she observed a plumber who was in to fix a leaky faucet helping himself to cookies from the same cookie jar. She might regard her son's behavior as morally wrong, but she would not consider it outrageous. She would be much more likely to be outraged by the plumber's action. It is not just that her son is someone with whom she closely identifies as kin, whereas she does not do so with the plumber. There is more to consider. Her son is a comember with her of her household. They are thus in a communal sharing relationship in regard to the household and many things in it. In stealing cookies from the jar, he is infringing on her rights in the authority aspect of their relationship, but he is not infringing on her domestic territory. They share that territory. The plumber, by contrast, is not a member of the household; he is not in a communal sharing relationship with its members in regard to the things in the household. He is not only infringing on the woman's authority as female head of the household, he is infringing on the domestic territorial rights of the household's members. His presumption is far greater than that of the woman's son. What is trespassed on is not the same.

With this example, I have brought the concept of territory and territorial behavior into the consideration of what may be relevant to understanding where moral outrage comes from. As defined by ethologists, a territory is a space that an individual or group is prepared to defend, and territoriality is a biologically programmed compulsion to defend such space, especially in males, but in some species also in females. When defending its territory against intrusion by a conspecific, an animal seems to have an enhanced power or energy. At the same time, the intruder seems to be inhibited by its sense that it is intruding and usually withdraws in response to the territorial defender's aggressive display. This special intimidating energy of the one and tendency to back down in response to it by the other is peculiar to territorial encroachment by 
conspecifics (Ardrey 1966, 3). I would add that, in humans, it appears that this same special intimidating energy is what distinguishes moral outrage from other forms of anger.

Ethologists have seen such behavior as functioning to space individuals more or less evenly over a larger area and its resources (Lorenz 1963, 30-31). The same can be said for territorial behavior by groups of animals. Since I consider territory to include what humans perceive as their rights and privileges, I find it logical to extend territorial behavior to involve dominance behavior within groups, such behavior relating to the establishment and defense of personal territories among individuals who at the same time share a larger territory. Clearly, I see territorial behavior in humans as representing something that goes back a long way in vertebrate phylogeny, however modified it may have been in the course of primate and hominid evolution. ${ }^{6}$ As will be evident in my treatment of territoriality, I do not see it as referring to an objectively defined physical space. Rather, I see it as referring to cognitively perceived relationships to external stimuli (of whatever kind) with which affective associations have been established through experience. The basis of those associations may be genetically built in (as with the taste of something sweet), or it may be acquired through conditioning. Territories, for other animals as well as for humans, are best understood as psychological and subjective rather than physical and objective.

But in humans, territoriality is complicated. The house in which I live is a part of my physical territory. The family of which I am a member is a part of my social territory. The various social identities to which I can lay claim — of gender, age, occupation, skill, social class, surname-are not only part of who and what I am as a social being, they are markers that delineate features of my social territory. All the different identity relationships that I am eligible to engage in-husband-wife, mother-son, employer-employee, citizen-policeman, for example—all such identity relationships give me both rights and duties in relation to others in the relationships. They also give me privileges in regard to some things and give the other parties privileges in regard to other things. My rights and privileges in these relationships are part of my personal social territory, and infringements on them are encroachments on that territory. ${ }^{7}$ Such infringements, whether failures or deliberate refusals to recognize who and what I am, are insults to my social persona. I bridle in response to them. Human anger, moreover, at breaches of people's rights is likely to have that extra energy shown by animals in defense of territory, that extra energy or intensity producing what we perceive as a person's moral advantage in defense of his or her rights. Except when an intruding person is committed to taking over another's territory, the intruder usually withdraws, or even apologizes, when confronted by the other's manifest outrage. ${ }^{8}$ 
There are people with whom we share many social identities and people with whom we share few. Some of the social identities we share with others, such as belonging to a particular family, may give us many territorial rights in common, while other shared identities give us few rights in common. Those people with whom we have many rights in common are the ones I am likely to identify with most closely, with whom I am likely to have a close sense of kinship. They are my natural allies. Such close identification is not confined to common family membership. It is likely to be felt by people who are members of the same work crew. It is well documented for those who were members of the same bomber crews in World War II (Grinker and Spiegel 1945). Ultimately, it is probably the sharing of experience that creates such emotional bonding and mutual identification, but the sharing of rights and duties is an important basis for sharing experience. In any social situation where people find themselves sharing territory in the sense that I am now discussing it, they look upon intrusions on their territory as insults to their collective identity and respond collectively.

In sum, then, I am suggesting that moral outrage is to be understood in relation to the phenomenon we call territoriality in animals. In humans, I am arguing, territoriality involves (among other things) social identities, rights and privileges in identity relationships, and the immunities the rights and privileges provide. Territoriality also involves the immunities that derive from our subjective understanding of what I have called principles governing social behavior. All of these things have to do with the self. Infringements on one's presumed immunities are encroachments upon what Erving Goffman has aptly termed "territories of the self" (1971, 28-61). Indeed, we can think of a social self as the sum of its territories.

Goffman's list of kinds of territories of the self provides a convenient review of what I have been talking about in connection with what people regard as their immunities. I present his list briefly as an illustration of the wide range of things that make up the subject matter of territory among human beings.

First is the "personal space" around an individual. Encroachment on it leads to resentment or withdrawal behavior. Edward T. Hall's studies $(1959,1966,1968)$ of what he calls "proxemics" document how the definition of personal space and its place in social relationships differs cross-culturally (see also Watson 1972); but in all societies there are understood definitions of personal space and of the conditions under which it may or may not be appropriately entered. Closely associated with personal space is what Goffman calls "the sheath," by which he has reference to one's physical body and immunities from contact with it and invasion in it. 
Goffman uses "the stall" to refer to such things as a particular chair in the living room, a particular bedroom, a particular parking space, or a particular place at the dinner table to which one has come to feel one has a priority right of access as a result of habitual use. What we call "squatter's rights" are obviously included here.

Objects that one identifies with oneself, such as what one wears on one's body or carries around-jewelry, clothing, handbags, briefcases, parcels, security blankets-make up Goffman's "possessional territory," which he equates with personal effects.

A common form of territory is "the turn." It includes such things as a place in line to which we have staked a claim and that we can then leave temporarily with the expectation of reclaiming it upon our return. Turns take many forms, and can be looked upon as the archetype of rights and duties in jural relationships. For me to claim a turn as my right means that others have a corresponding duty to let me have my turn. Turns include such things as having our turn at talk and having our day in court. They include virtually all of what we call our "entitlements."

"Use space" is Goffman's term for the area around us that we need to have free from intrusion by others in order to carry on with a task of some kind. It is the space we refer to when we tell children not to get in our way while we are working. It is a temporary territorial claim contingent on our being engaged in what is recognized as an appropriate activity.

Goffman's "informational preserve" refers to facts concerning ourselves to which we expect to control access: things, in short, that others do not have a right to know unless we give permission. We see encroachments on such informational preserves as invasions of privacy. Linked with this is the last kind of territory of the self in Goffman's list, what he calls "conversational preserve." This involves the privilege of control over whom we do or do not talk to, its exercise exemplified by the well-worn phrase "no comment." It also involves the privilege of excluding someone from a private conversation.

These rights and privileges and the immunities that flow from them are applicable or not depending on the respective social identities of those in a given encounter. As a child, for example, I had little in the way of informational preserve in relation to my parents. They had a right to know things about my personal life that I did not want them to know. When I became an adult, they lost that right, and my informational preserve expanded in my dealings with them. All of these kinds of territories, moreover, are differently involved in the communal sharing, hierarchical, identical treatment, and contractual modes of social relationships. Thus, if my wife and I have separate checking accounts (identical treatment mode), we are not as free to go to one another's wallets 
for money as we are if we have a joint account (communal sharing mode). Whether we manage our money on a basis of sharing or of equal entitlement to autonomy, however, is our joint privilege to determine, and others have no right to determine it for us.

It should now be clear that territories of the self-the territories that constitute our social selves - are ever present as considerations in social interaction. Where we stand with one another in regard to them all, and in what relational mode, is something we must take account of as regularly and pervasively as we take care in our speech that nouns and verbs agree in number or decide whether the third person singular pronoun should be he, she, or it. As with grammaticality in speech, moreover, our attention is called to these territories of the self only when people do not behave as we expect them to.

\section{SELF-INVOLVEMENT AND INTENSITY OF OUTRAGE}

We come now to emotional considerations relevant to understanding moral outrage. There is obviously more to the expression of outrage than feelings of intrusion on culturally constructed territories of the self. We react mildly to some intrusions and violently to others. I have already mentioned our degree of identification with the intruder as a factor in this, but we have also to consider the emotional value or symbolic importance for us of what is intruded upon. We see some intrusions as desecrations, but not others. Intrusions on our physical selves usually evoke more violent responses in us than do intrusions on our turn in a conversation. The closer an intrusion comes to the core of our self-territory, the more outraged we become. But there are other things besides this to consider.

Think of an occasion when a three-year-old boy's visiting playmate is drawn to one of his toys. The child may not be perturbed by this. On the other hand, the toy may suddenly acquire new value for him because his friend wants it. He comes over and takes a defensive or threatening stance toward his friend, showing his objection to the friend's playing with his toy. Or, again, he may be mobilized to violent behavior, running over and grabbing the disputed toy and making loud protest when his mother tells him he should share it with his friend. His toys are an important part of his personal territory, but some of them are obviously more important to him than others.

Consider, again, a situation where a man is cleaning out his closet and getting clothes ready to give away to a charitable organization. He is quite happy to dispense with some, but there are others that he insists on keeping, even if they are somewhat frayed. There may be a particular tie that he especially liked to display himself in. Or there may be a present his wife gave him before they were married, something that has 
always made him think fondly of her and of the specialness of their relationship. There may be a shirt he wore when he won a tennis tournament. These things have sentimental value for him. People value the things they associate with the way they like to think about themselves, the way they want others to perceive them, and they value the things that make them feel most secure in who and what they are. Athletes like to display their trophies in their household's place of honor, such as the mantel in the living room. Sentimental value in some cases may be so great as to make an object sacred, inviolate, or taboo.

Consider, too, what happens when a mother comes to visit her fourteen-year-old son at school, and in front of his schoolmates begins to behave to him in a mothering way. She could still behave to him that way in the privacy of their home without his objecting, but for her to do it in public is devastating, especially in front of his friends, who will be sure to tease him about it afterwards. $\mathrm{He}$ and his friends, now in their early teens, are working hard to cultivate an adult identity for themselves, an identity whose territories of the self differ from those of a child. His mother has denied him the ability to maintain a muchsought-after image of self in the presence of his peers. He is outraged. How could she do this to him? Ten years later, he could be more forgiving; his identity as an adult would no longer be at issue.

What I am calling attention to here is the obvious fact that people work to develop and maintain what they desire as social selves, to develop and maintain the territories that their social selves comprise. Among other things, these territories include social identities and the social relationships involving those identities in which people can feel comfortable with themselves and, on occasion, really good about themselves. People tend to be especially insistent on the rights and privileges pertaining to identities they are actively cultivating for themselves and to be especially scrupulous about displaying the badges of those identities. A newly inducted member of a prestigious social club is likely to be a more scrupulous observer of its dress code than a longtime member.

We are especially sensitive to encroachment on features of personal territory that are symbolic of aspects of self that we want very much to maintain or to consolidate. Most important are those aspects of self from which we feel we derive our worth as persons and that are most essential to who and what we feel ourselves to be. We consider these things to be sacred and inviolate. Understanding what we mean when we call something sacred requires our taking account of the emotional value of features of both the territories of individual selves and the collective territories of groups with which individuals identify themselves. If encroachment on what is sacred to us is especially evocative of moral outrage, then whatever it is that imparts sacredness to things at the same 
time associates with those things our concern for the scrupulousness of behavior that we equate with morality. This is true whether these things are people, doctrines, objects, or symbolic acts. ${ }^{\text {? }}$

We also must consider how outrage, as an emotion, is subject to the psychological processes that affect emotional intensity and that also affect the way emotions are directed or deflected toward other persons and things.

Frustration plays an important role in this regard (Dollard et al. 1939). It does not in itself produce moral outrage (Sabini and Silver 1982, 164-66), but it does produce feelings of anger, mounting feelings of desire to strike out at something. A minor encroachment on one's personal territory or a minor infringement of one's rights that would normally produce little reaction can evoke an unexpected outburst of moral outrage when a person's mounting anger as a result of frustration in regard to something else is deflected (in clinical parlance displaced) onto the encroacher, whose encroachment legitimizes releasing the anger. That the intensity of outrage is out of proportion to the encroachment results from the already pent-up anger over something else.

When the intensity of our outrage strikes others as inappropriate, we may be inclined to try to find ways of justifying it through rationalization and projection. We may attribute to the encroacher motives in regard to ourselves and our rights that would justify our expression of outrage. A person who is beset by chronic anger that is in need of legitimation may project upon others hostile intentions, as in clinical paranoia, thereby giving moral justification to his anger and to his hostility toward them. When people are angry, they regularly seek to justify their anger and give it moral sanction. Litigious accusations and arguments among American children illustrate this. In war we are quick to portray our enemy as morally monstrous and undeserving of the consideration due to fellow human beings. Thus we mobilize moral outrage and use it to foster concerted public effort. Thus, also, we justify to ourselves what others perceive as our own morally monstrous behavior.

Even when it is not directed at them, people are likely to express outrage at behavior in others that they take care to avoid doing themselves, even when tempted to. I share an obligation with my fellows to cultivate a social self as someone who is honest and can be trusted. I make sacrifices to do this, inhibiting desires to cheat or even denying to myself that I have them. I can demand of my fellows that they do the same. If I have scrupulously avoided cheating on examinations, for instance, I feel that people who cheat are taking unfair advantage of me. If they can get away with it, they will have cheapened the self I have cultivated. They will have made a mockery of my adherence to the rules. My outrage and insistence that they be punished is a 
response to an invasion of the territory I have staked out for myself as an honest person. My vehement reaction is typical of what is clinically called a reaction formation. ${ }^{10}$

Reaction formation as I have just illustrated it is critical in providing "a psychological foundation for emotional commitment to the sanction systems by which people seek to enforce compliance with their public code of conduct" (Goodenough 1963, 127). Having learned to inhibit impulses within ourselves, we come to feel strongly about right and wrong. Without problems of self-control in the maintenance of our social selves, we would have no need for an emotional commitment of self to our social rules. They would concern us only as their breach was an infringement of our personal rights. There are, indeed, some people who invoke rules when they stand to gain by doing so, but who ignore them otherwise. Such people do not meet with general approval. The self-denial that goes into cultivating and maintaining our social selves gives value to the rules of behavior by which we live and contributes to the sanctity some people attribute to law. The intensity of outrage engendered in the process of reaction formation can be seen as communicating and reinforcing commitment by individuals to observing and maintaining their society's rules, a commitment without which no community can endure.

As the foregoing suggests, people tend to react with moral outrage against those things whose existence puts at risk their ability to maintain aspects of their social personae that they most cherish. Not just the rights and duties we enjoy, but our very identities - who and what we are-define our territories of self. What puts our sense of self at risk may, like pornography, be things of which we publicly disapprove but to which we are privately attracted and about which we are conflicted. Their existence is thus a threat to the integrity of the self we wish to maintain. We may resolve the conflict by committing ourselves to crusades against them.

More important, we may feel similarly threatened when others profess beliefs or have customs different from our own. We are especially threatened if such professions or practices by others raise questions about the validity of beliefs and customs that are crucial (or symbolically so) to the identities to which we are committed. The very existence of people with different beliefs and customs may be seen as morally outrageous and therefore intolerable. Especially threatening are those with whom we have a sense of shared identity in other respects, who should therefore have all the more reason to believe as we do. We tend to be especially outraged by the heretic and the apostate.

So we see that moral outrage not only serves to hold us together in social groups and reinforce community; it also serves to exacerbate feel- 
ings about human differences of group membership, nationality, culture, and religion, differences whose very existence can cause outrage.

\section{THE SELF AND THE TERRITORIES OF OTHERS}

So far I have dealt with territories of the self, territories that play an important role in defining a person's social self. I have done so because it is in this respect that we see how territoriality relates to human feelings and expressions of moral outrage. Before concluding this presentation, however, I should say something about the self in relation to the territories of others.

Each of us is born as a socially and emotionally significant object in the family territory of our parents. We are accepted by them as fellow sharers of that familial space and as fellow sharers of many of the most intimate regions of our parents' personal territorial space. As we mature, we acquire friends, whose friendship is manifested by their willingness to admit us into their personal spaces and share them with us. What we call love, or caritas, is revealed by our acceptance of others as sharers of our territories, and we experience love through their acceptance of us as sharers in their territories. Such acceptance on a temporary basis is the essence of what we call hospitality.

Humans, we recognize, need love in order to be emotionally whole. We want to be accepted as a family member, as a neighbor, as a fellow member of a community, as someone others will admit to their homes and clubs. We have a built-in emotional need to be allowed to share territory with others, at least some others. We feel it is morally imperative, therefore, that people be willing to engage in some degree of territorial sharing with one another. From this comes community. The communal sharing mode discussed above is essential to human existence. At the same time, we each have our personal territories, and we make communal sharing contingent on others' showing respect for them. The hierarchical mode of differential right and privilege is also an inevitable part of human existence.

The territories we share with others are part of our own personal territory. We resent encroachments on them by outsiders, and we tend to be wary about the admission of additional sharers. Indeed, we find that the value of being included as a sharer of the territory of a family, community, or club is diluted by the inclusion of others as cosharers. A child is likely to resent having to share familial space with a younger sibling. Club members are likely to want to keep membership exclusive. Those territories from which we derive the greatest value are the ones we are likely to be least willing to share with others. Thus, there is an ongoing tension between our desire to be included by others and our desire to preserve for ourselves the value of what we share by excluding others. This tension is 
productive of what we are likely to experience as moral dilemmas. The implications of territoriality for the human sense of morality and what humans experience as love and jealousy seem to be far-reaching indeed.

\section{CONCLUSION}

In this discussion I have focused on moral outrage. Only by implication have I dealt with morality as such and what it consists of, though I have briefly pointed to the processes that I think give rise to a moral sense in people.

I have argued that moral outrage is a response to what people feel is an infringement of a right or privilege of their own or of those with whom they identify, whether as members of the same social group or as fellow humans. Rights and privileges in a formal sense are explicit expressions of subjectively felt principles that people acquire in the course of learning to function acceptably as members of social groups.

These rights and privileges, if respected by others, provide individuals with immunity from encroachments on their persons, on things that they value, and on their privacy. These immunities provide people with strong incentives to maintain their society's rules of conduct, even though they are often tempted to break them. The rights and privileges a person enjoys, together with the identities with which these rights and duties are associated, constitute a large part of his or her social territory -what Erving Goffman (1971, 28-61) has referred to as "territories of the self." From this perspective, infringements of rights and privileges and demeaning redefinitions of identity constitute encroachments on one's territory. The moral outrage such encroachment evokes appears, therefore, in the symbolically structured social world in which humans live, to be an expression of what is equivalent to territorial behavior in other animals. It seems that moral outrage is how the ethological phenomenon of territorial behavior is manifested among humans.

This discussion has led us to view the cultural organization of social relations as consisting of agreed-upon understandings regarding kinds of selves and the rights, privileges, and immunities that constitute the territories of these selves. Mutual respect for one another's territories is what allows societies to function, and that respect is fostered and reinforced by the emotional response that infringements of our respective territories evoke in us - the response we call moral outrage. Moral outrage is essential to the maintenance of social life, as well as being potentially destructive of it. Similarly, the human need to share in the territories of others contributes to both the maintenance of community and the tendency to exclusiveness in that maintenance.

I close by returning to where we began, to the apparent fact that moral outrage is something we feel toward others and not toward our 


\section{own selves. We are all at the center of our own territories and cannot encroach upon them. Only others can do that.}

\section{NOTES}

In the formulation of this paper, I owe much to discussions with Oliver R. Goodenough, my son, who has thought deeply, in connection with legal theory, about the mix of biological and cultural factors that provides humans with a sense of fairness, equity, and justice.

1. In this I differ from Sabini and Silver (1982, 163-82), who treat anger as occurring only in the context of a "transgression." Their treatment of anger is entirely in relation to morality, and hence for them anger is the equivalent of what is here termed moral outrage. I would argue that if I am trying to fix a broken piece of furniture and am repeatedly frustrated in my efforts to do so, the emotion rising within me is one I would identify as anger. If I am on my way to an important appointment and my car gets a flat tire, I am likely to be extremely, however impotently, angry. Such frustration of intentions does produce anger. But the anger it produces does not have a moral basis; it does not involve a transgression against us by some other person, and we do not feel outrage. Our anger may carry over, however, into a situation in which we flare up with moral outrage at some otherwise very minor transgression.

2. Elizabeth Marshall Thomas (1993) shows how such processes appear to have been at work in her dog community. She carefully avoided providing any training for the young born into it, yet by learning from the other dogs, the pups became housebroken on their own and in other respects fit themselves behaviorally into the routines the dogs had developed for themselves. This was evident even in two dogs that had been adopted by dogs not their biological mothers, for they patterned themselves after their respective adoptive mothers.

3. Differences in temperament and other personality factors also affect the relative importance people attach to different rights and privileges as well as the intensity with which they react to infringements of their rights. There may be gender differences as well.

4. Among chimpanzees, we see the sharing of abundant food resources within the local group. An individual who finds a grove of fruit or nuts ready to eat lets out a call that brings other members of the group to join in the harvest (Goodall 1986). There are also occasions when they don't share; more dominant individuals assert their claim at the expense of less dominant ones, who back off. Among vervet monkeys, mothers share access to food with their young. Among these monkeys, moreover, less dominant individuals ally themselves with dominant ones, who allow their less dominant allies to share in the enjoyment of a food resource (Cheney, Seyfarth, and Smuts 1986). Descriptions of sharing and dominance behavior are also provided by James Silverberg and J. Patrick Gray (1992). Sharing among dogs and wolves is described by Elizabeth Marshall Thomas (1993).

5. Alan Page Fiske (1991), from whom I have taken these modes, labels them "communal sharing," "authority ranking," "equality matching," and "market pricing," respectively. He persuasively demonstrates the many, complicated ways in which they are manifested in human social life.

6. I disagree with Takayoshi Kano $(1986,222)$, who sees human territoriality as a late emergent, following the development of agriculture, although I agree with his implication that human territorial behavior has been much affected by the increasing complexity of the meaningful spaces humans occupy as a result of cultural elaboration through human history.

7. Robert Ardrey (1966) equates territory in humans with property. He treats property as things of value, but it is better understood not as valued things but as freedom of access to such things and freedom from concern about the loss of such access. In human society such freedom of access derives from rights and privileges, and freedom from concern about the loss of such access derives from the immunities those rights and privileges convey.

8. We may ask whether this tendency to withdraw in the face of a suddenly intense response has a connection with the apparent tendency among young animals "to approach, with part or all of the body, sources of stimulation which are quantitatively low, regular, and limited in range of magnitude, and withdraw from those which produce inputs which are high, irregular, and of extensive ranges" (Hinde 1966, 361, citing the suggestion by T. C. Schneirla 1965). Robert A. Hinde $(1966,361,365)$ cites other work that is consistent with Schneirla's suggestion.

9. For self-maintenance as a concern that imparts to human behavior the quality of personal involvement that we intuitively recognize as religious when we encounter it in others, see Goodenough (1988). 
10. For an explication of the clinical terms displacement, rationalization, projection, and reaction formation, as used here, see Ruth L. Munroe (1955).

\section{REFERENCES}

Ardrey, Robert. 1966. The Territorial Imperative. New York: Atheneum.

Cheney, Dorothy, Robert Seyfarth, and Barbara Smuts. 1986. "Social Relationships and Social Cognition in Nonhuman Primates." Science 234 : 1361-66.

de Waal, Frans B. M. 1989. "Food Sharing and Reciprocal Obligations among Chimpanzees." Journal of Human Evolution 18 : 433-549.

1991. "The Chimpanzee's Sense of Social Reciprocity and Its Relation to the Human Sense of Justice." American Behavioral Scientist 34 : 335-49.

1994. "Sex Differences in the Formation of Coalitions among Chimpanzees." In Primate Politics, ed. G. Schubert and R. D. Masters, 128-40. Lanham, MD: Univ. Press of America.

Dollard, J.; L. W. Doob; N. G. Miller; O. H. Mowrer; and R. R. Sears. 1939. Frustration and Aggression. New Haven: Yale Univ. Press.

Fiske, Alan Page. 1991. Structures of Social Life: The Four Elementary Forms of Human Relations. New York: Free Press.

Goffman, Erving. 1971. Relations in Public: Microstudies of the Public Order. New York: Basic Books.

Goodall, Jane. 1986. The Chimpanzees of Gombe. Cambridge: Harvard Univ. Press, Belknap Press.

Goodenough, Ward H. 1963. Cooperation in Change: An Anthropological Approach to Community Development. New York: Russell Sage Foundation.

1988. "Self-Maintenance as a Religious Concern." Zygon: Journal of Religion and Science 23 (June): 117-28.

Grinker, Roy R., and John P. Spiegel. 1945. Men under Stress. Philadelphia: Blakiston.

Hall, Edward T. 1959. The Silent Language. New York: Fawcett. 1966. The Hidden Dimension. New York: Random House.

1968. "Proxemics." Current Anthropology 9 : 83-108.

Hinde, Robert A. 1966. Animal Behavior: A Synthesis of Ethology and Comparative Psychology. New York: McGraw-Hill.

Hohfeld, Wesley Newcomb. [1919] 1946. Fundamental Legal Concepts. Ed. W. W. Cook, with a new foreword by A. L. Corbin. New Haven: Yale Univ. Press.

Kano, Takayoshi. 1986. The Last Ape: Pygmy Chimpanzee Behavior and Ecology. Stanford, Calif.: Stanford Univ. Press.

Lorenz, Konrad. 1963. On Aggression. New York: Harcourt, Brace and World.

Munroe, Ruth L. 1955. Schools of Psychoanalytic Thought: An Exposition, Critique, and Attempt at Integration. New York: Dryden Press. See especially Chapter 6.

Sabini, John, and Maury Silver. 1982. Moralities of Everyday Life. Oxford: Oxford Univ. Press.

Schneirla, T. C. 1965. "Aspects of Stimulation and Organization in Approach/Withdrawal Processes Underlying Vertebrate Behavioral Development." In Advance in the Study of Behavior I, ed. D. Lehrman, R. A. Hinde, and E. Shaw. New York: Academic Press.

Silverberg, James, and J. Patrick Gray. 1992. Aggression and Peacefulness in Humans and Other Primates. New York: Oxford Univ. Press.

Thomas, Elizabeth Marshall. 1993. The Hidden Life of Dogs. Boston and New York: Houghton Mifflin.

Watson, O. Michael. 1972. Symbolic and Expressive Uses of Space: An Introduction to Proxemic Behavior. Reading, Mass.: Addison-Wesley Modular Publications, no. 20. 